\title{
Farm characteristics and calf management practices on dairy farms with and without diarrhea: A case-control study to investigate risk factors for calf diarrhea
}

\author{
D. Klein-Jöbstl, ${ }^{1}$ M. Iwersen, and M. Drillich \\ Clinical Unit for Herd Health Management, University Clinic for Ruminants, Department for Farm Animals and Veterinary Public Health, \\ University of Veterinary Medicine Vienna, 1210 Vienna, Austria
}

\begin{abstract}
Calf diarrhea is one of the most important problems in calf rearing on dairy farms worldwide. Besides pathogens, several noninfectious management factors, especially management around birth, colostrum management, calf housing, feeding, and hygiene are important in the pathogenesis of diarrhea. To date, few data are available concerning calf rearing management on small and medium-sized dairy farms that are typical for Austria and the alpine region. Consequently, the objectives of this case-control study were to evaluate routine calf management practices on Austrian dairy farms and to examine differences in management between farms with and without the presence of calf diarrhea to identify risk factors. Overall, 100 dairy farms were visited. Of these farms, 50 were chosen based on the history and presence of calf diarrhea (case farms). Another 50 farms with no presence of calf diarrhea were chosen to serve as a standard of comparison (control farms). On farms, management was evaluated by face-to-face interview, and health status and hygiene were surveyed. Several calf rearing management procedures were similar on all of the visited farms, especially in areas regulated by national and European law. These factors include colostrum management and feeding. Consequently, no influence of these factors on the appearance of calf diarrhea could be detected. In contrast, other areas such as hygiene measures differed between farms and showed a partial association with the presence of calf diarrhea on farm. Variables related to diarrhea on farm were farm size; that is, the number of cows on farm. Farms with diarrhea cases were larger (median 40 cows, interquartile range 24.5 to 64.0 ) compared with farms with no presence of diarrhea (median 28 cows, interquartile range 18.8 to 44.0 ). Other risk factors that influenced the presence of diarrhea were the presence of other farm animal species on the farm [odds ratio (OR) 26.89, 95\% confidence interval (CI): 2.64 to 273.5], frequency of
\end{abstract}

Received November 8, 2013.

Accepted April 19, 2014.

${ }^{1}$ Corresponding author: Daniela.Klein@vetmeduni.ac.at cleaning of the calving area (OR $0.12,95 \%$ CI: 0.02 to 0.79 ), the placement of individual calf housings (barn vs. outdoors; OR 0.02, 95\% CI: 0.00 to 0.47 ), and the presence of respiratory tract disease (OR 52.49, 95\% CI: 1.26 to $2,181.83)$. The possible influence of these factors on the appearance of calf diarrhea should be considered when farmers are advised.

Key words: diarrhea, dairy calf, management

\section{INTRODUCTION}

Calf management, especially calving management, care of the newborn, colostrum management, calf housing and feeding, as well as hygiene, has an important effect on calf performance and health. The most important health concern is calf diarrhea, resulting in the greatest economic loss in this age group (Torsein et al., 2011). Diarrhea is a complex, multifactorial disease with numerous infectious and noninfectious factors. Factors influencing the pathogenesis of diarrhea are pathogen exposure, environmental conditions, management, nutritional state, and immune status.

Different studies have aimed to identify risk factors for the presence of calf diarrhea, sometimes with contradictory results. Bendali et al. (1999), for example, reported that cow cleanliness and cleaning of the barns after the calving season may prevent diarrhea. Similar results were obtained in a prospective cohort study by Frank and Kaneene (1993). Pithua et al. (2009) compared the prevalence of diarrhea and other diseases in calves in regard to cleaning the calving area. In that study, the risk for diarrhea or any other calf disease was not different between groups, indicating that management factors other than the calving pen had a greater influence on calf health. Regarding colostrum supply, few authors could determine statistically significant effects. The origin of colostrum and route of colostrum feeding (nipple or bucket versus suckling) have been associated with the occurrence of diarrhea (Svensson et al., 2003; Lundborg et al., 2005). Furthermore, the concentration of $\operatorname{IgG}$ was related to diarrhea (Berge et al., 2009). 
Additional factors associated with diarrhea were breed (Lundborg et al., 2005; Svensson and Liberg, 2006; Svensson et al., 2006), the placement of indoor calf pens against an outer wall compared with pens separated from outer walls (Lundborg et al., 2005), keeping grouped calves on a slatted concrete floor versus other floors, housing in freestalls compared with tiestalls, purchasing calves (Gulliksen et al., 2009), and calf stocking density (Bendali et al., 1999).

In Europe, some management and environmental factors concerning calf rearing are regulated by law (Council Directive 2008/119/EC; European Community, 2008). This European directive is specified in some areas by Austrian legislation (Tierhaltungsverordnung, 2004). Regulated areas are colostrum support within the first $6 \mathrm{~h}$ postpartum and some aspects of calf housing and feeding. In contrast, although the importance of hygienic measures is known (Weaver et al., 2000), they are not regulated.

Little data are available concerning calf management on small and medium-sized dairy farms as typical for Austria. Thus, the objective of the present study was to evaluate routine calf management practices on Austrian dairy farms and to define risk factors for the presence of calf diarrhea in a case-control study.

\section{MATERIALS AND METHODS}

\section{Experimental Design}

One hundred dairy farms in Austria were visited and evaluated once by the same person from September to March of 2009-2010. To recruit case farms, local veterinarians of 2 areas in Austria, Lower Austria and Styria, were asked to provide lists of dairy farms with a documented problem of calf diarrhea during the past year. A farm with diarrhea problems was defined as a farm with multiple treatments by the veterinarian for calf diarrhea. Out of these lists, farms were randomly chosen, and farmers were contacted in the week before the planned visit, asked if problems with calf diarrhea were still present on farm, and asked whether they were willing to participate in the study. Farms were only enrolled into the study when at least one calf suffered from diarrhea at the farm visit. Five farms refused to participate and another 7 of the contacted farms had no actual cases of diarrhea. To define cases of diarrhea, feces of preweaned calves was evaluated as described by Larson et al. (1977), where scores 3 (runny, spreads readily to about $6 \mathrm{~mm}$ depth) and 4 (watery, liquid consistency, splatters) were categorized as diarrheic.

Local veterinarians were asked to identify additional farms to serve as control farms, from the same geographical region and of similar structure but with no history of calf diarrhea problems and no current diarrhea cases. To achieve good similarity in structure, the type of farm (conventional or organic), the type of cow barn (freestall or tiestall), and the number of dairy cows were used as further criteria. The farms that best fit these criteria were contacted and visited at the same time as the farms with diarrhea. If no suitable farm was available in the same geographical region or the farms did not want to participate in the study (17 farms), the next best fitting farm was chosen. Farms were excluded as control farms if one or more calves suffered from diarrhea at the time of the visit; this was the exclusion criterion for 7 farms. Presence of other diseases did not exclude a farm from the study.

A sample size of 50 case and 50 control farms provides $95 \%$ confidence of detecting an odds ratio of $\geq 3.5$ ( $80 \%$ statistical power), assuming a minimum of $20 \%$ of control farms exposed to the factor of interest (Thrusfield et al., 2001).

A questionnaire was used to collect data during a face-to-face interview with the farm owner or manager. Areas of interest were farm characteristics, health status of the animals, calf housing and feeding, focusing on calves within the first weeks of life, management practices around calving and birth, as well as hygienic measures. Calf rearing areas were visited and hygiene was evaluated as described by Lundborg et al. (2005). To evaluate calf hygiene, the legs, thighs, and ventral abdomen of up to 5 randomly chosen preweaned calves were scored. The percentage of the body part that was contaminated with feces was documented (0 to 100\%). Furthermore, the pen walls and bedding material of up to 5 individual and group calf housings for preweaned calves were scored. A value of 0 to $5 \%$ described a clean area, 6 to $30 \%$ a mildly dirty area, 31 to $70 \%$ a moderately dirty area, and $>70 \%$ a severely contaminated area.

Depending on farm size, up to 5 randomly chosen preweaned calves were examined by the same person according to the clinical examination of ruminants (Radostits et al., 2007). This examination included evaluation of behavior and general appearance, posture, body condition, body conformation, skin (including umbilicus), head (eyes, nostrils, mouth), thorax (respiratory rate, rhythm, depth, type, and noises), pulse, auscultation of the lung and heart, and abdomen. Respiratory tract disease was defined as severely increased respiratory sounds at lung auscultation or as moderately increased respiratory sounds together with additional signs, such as dyspnea, coughing, or nasal discharge. By definition, an umbilical infection was diagnosed when at least 2 of the 3 following signs were present: local swelling of the external umbilicus, increased local temperature, and pain. 
Table 1. Overview of general farm characteristics on the 100 visited farms

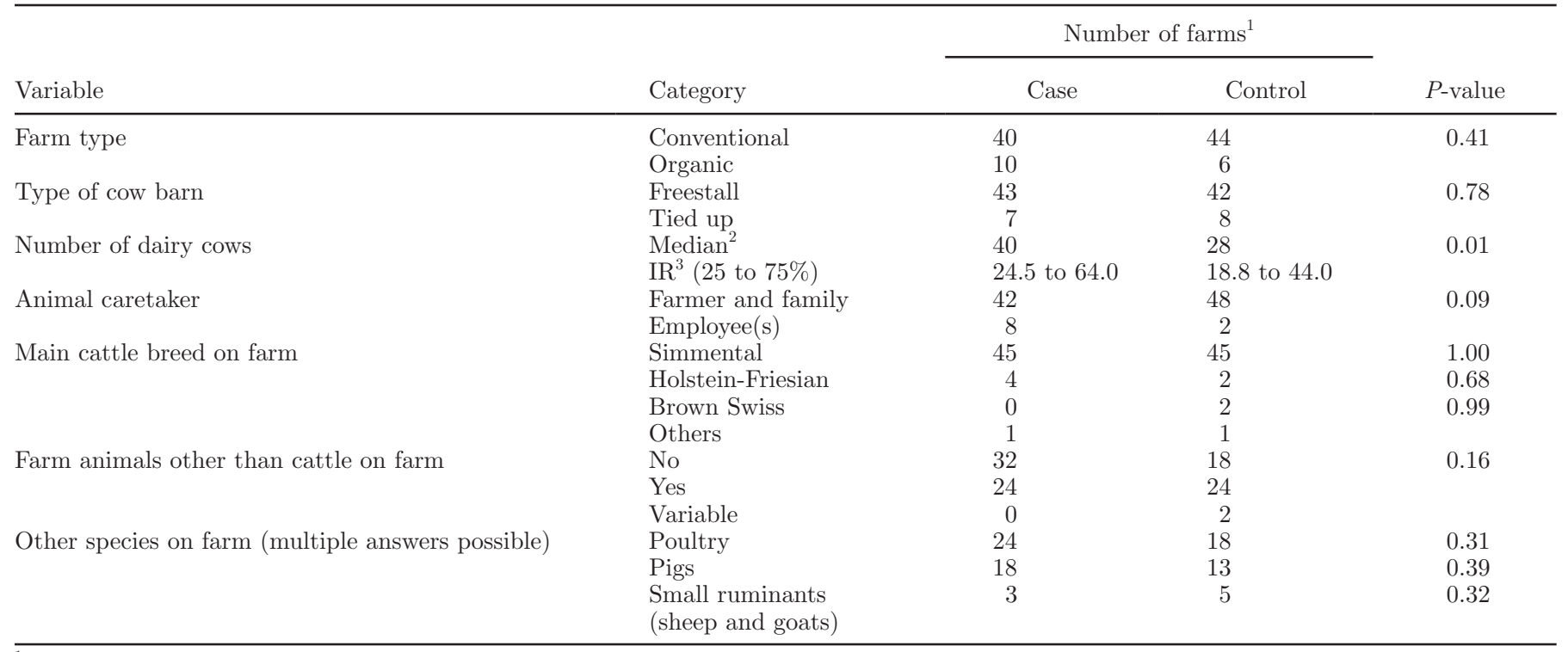

${ }^{1}$ Case farms are farms with the presence of diarrhea; control farms are farms without calf diarrhea.

${ }^{2}$ Variable was not categorized; continuous variable.

${ }^{3} \mathrm{IR}=$ interquartile range.

\section{Data Analysis}

Data were analyzed using PASW (version 20.0; IBM Corp., New York, NY). Descriptive statistics were calculated to describe farm characteristics and management practices. The association of farm characteristics and management factors with the occurrence of calf diarrhea was tested in a 2-step process. The association between the appearance of diarrhea on farm and the evaluated factors was analyzed by $\chi^{2}$ test, Fisher's exact test if in one field the number was $<5$, or univariable regression tests for each binary or categorical variable. Student's $t$-tests were performed to compare normally distributed continuous variables and health status (diarrhea present vs. not present), and the MannWhitney U-test was used for not normally distributed continuous variables. Variables with a $P$-value $\leq 0.2$ were included in a multiple logistic regression model using presence of diarrhea on farm as a binary outcome variable (present vs. not present). All variables were tested for correlation by Pearson or Spearman rank correlation coefficient before entering the model. If a correlation of $>60 \%$ was given, one of the covariates was discarded. A backward stepwise elimination of nonsignificant variables was performed to obtain a minimal model containing only significant variables $(P<0.05)$. Herd size was forced into the model as a confounder. Model fit was evaluated with the Hosmer-Lemeshow test for 10 groups.

\section{RESULTS}

Farm characteristics, with the exception of the number of cows, were similar between the visited farms as shown in Table 1. The median number of dairy cows was 34 [interquartile range (IR; 25 to $75 \%$ ): 22 to 50], whereas on farms with diarrhea the median number was 40 and on farms without diarrhea the median number was 28 cows.

\section{Management Around Calving and Care of the Newborn}

Data concerning management around calving and care of the newborn calf are presented in Table 2. A calving pen or box was present on 69 farms, with a significant difference between farms with (40) and without (29) diarrhea. Another significant difference between farms with and without diarrhea was detected in cleaning frequency of this area. Questions in terms of "care of the newborn" included the time of cow-calf separation after birth, first colostrum supply, and umbilical care. On most of the farms (76), calves were separated from their dam immediately after birth or recognition of birth by the farmer if the calf was born unattended. On 20 farms, calves were usually separated within 24 $\mathrm{h}$ after birth; on the remaining 4 farms, calves were separated later than $24 \mathrm{~h}$ after birth. On almost all farms (99), the owner or manager stated that each calf 
Table 2. Summary of management around calving and care of the newborn calves on the 100 visited farms

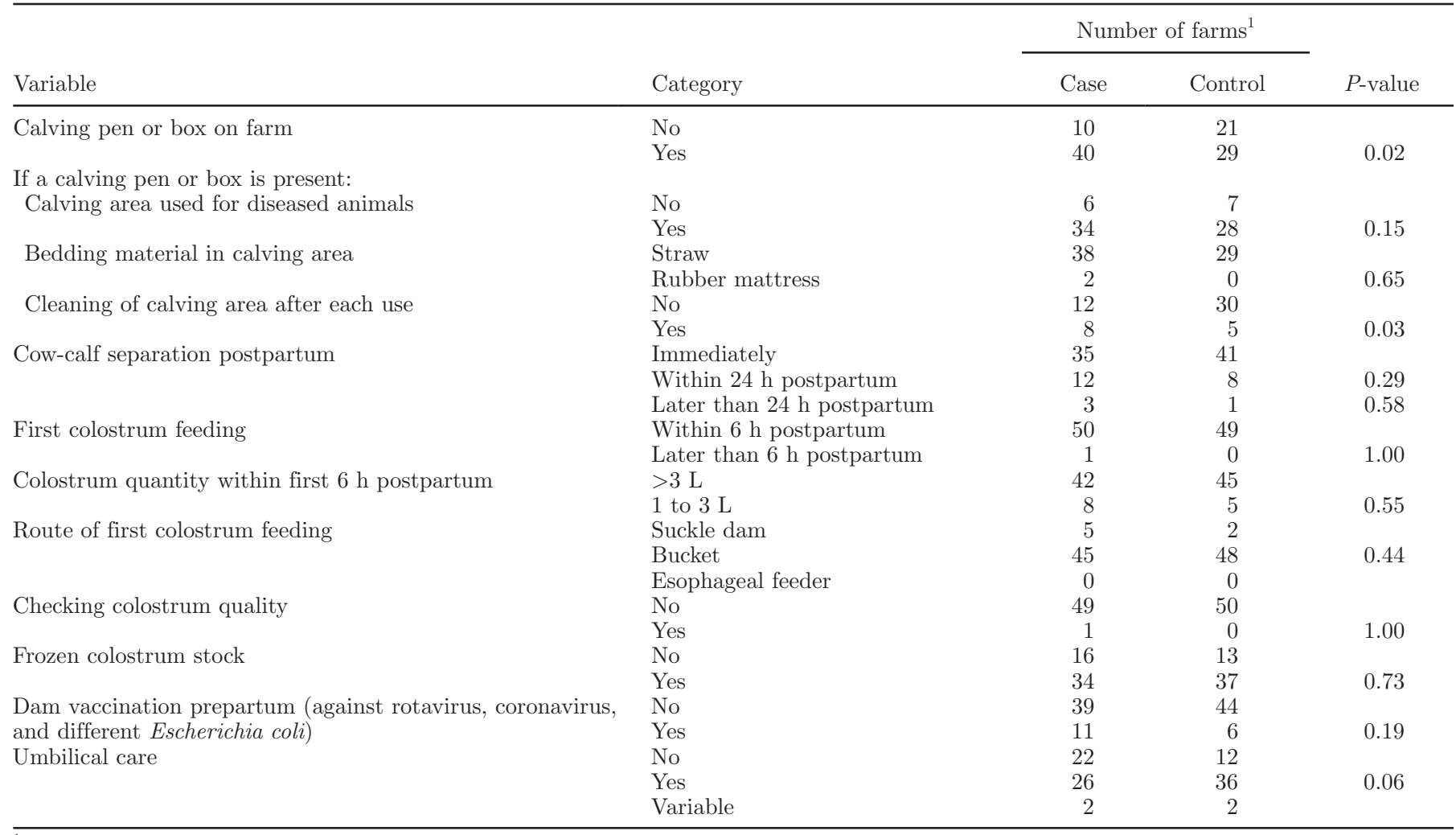

${ }^{1}$ Case farms are farms with the presence of diarrhea; control farms are farms without calf diarrhea.

received colostrum within $6 \mathrm{~h}$ after birth; on 7 farms, calves were allowed to suckle their dam. Esophageal feeders were not routinely used on any of the farms, but this option was left for exceptional cases. Only on one of the farms colostrum quality was determined by use of a hydrometer.

Umbilical disinfection was performed on 34 of the farms, where iodine, antimicrobial-containing sprays, foreshot (the impure spirit produced in the first stages of distillation), or schnapps (distilled alcohol with a minimum of $15 \%$ alcohol by volume) was used.

Prepartum dam vaccination against rotavirus and coronavirus as well as different species of Escherichia coli was performed on 17 farms. This was a standard procedure on 6 farms without and 11 farms with the presence of diarrhea. None of these variables differed between case and control farms.

\section{Calf Housing}

Calf housing characteristics are summarized in Table 3. On 99 farms, calves were housed individually after birth, usually for 1 to $12 \mathrm{wk}$, with a median of $6 \mathrm{wk}$. On 66 farms ( 38 case and 28 control farms), calves were already grouped preweaning, and on the remaining 34 farms, calves were grouped after weaning. Preweaning calves were kept in groups of 2 to 30 animals (median 6 ), mainly with animals of different ages. Calves were housed individually within the cow barn on 40, in facilities for calves and young stock on 12, outdoors on 21 , and indoors and outdoors depending on number of calves and season on 26 of 99 farms. Significant differences were found between farms with and without diarrhea when a combination of indoor and outdoor housing was used compared with outdoor housing of all calves. Outdoor housing of all calves was more common on control farms compared with farms with diarrhea (case farms). All preweaned calves were housed on straw. Individual housings were cleaned daily only on 6 farms. On all other farms, the farmer indicated that fresh straw was added if necessary, and pens were cleaned after the calf left the box.

\section{Calf Feeding}

Standard calf feeding procedures on the visited farms are summarized in Table 4. Calves were fed with whole milk on 84 farms. Waste milk (milk from cows treated with antibiotics and from cows with mastitis) was offered to calves on 82 farms, but to male calves only on 48 farms. On most of the farms (96), milk or milk replacer was fed restricted to 10 to $12 \%$ of the calf 
Table 3. Data on calf housing on the 100 visited farms

\begin{tabular}{|c|c|c|c|c|}
\hline Variable & Category & \multicolumn{2}{|c|}{ Number of farms ${ }^{1}$} & $P$-value \\
\hline Individual calf housing postpartum & No & 1 & 0 & \\
\hline \multirow{2}{*}{ Days of individual calf housing postpartum } & Median $^{2}$ & 42 & 42 & 0.18 \\
\hline & $\operatorname{IR}^{3}(25$ to $75 \%)$ & 21 to 56 & 14 to 56 & \\
\hline Type of individual calf housing & Synthetic igloo & 6 & 10 & \\
\hline Bedding material & Others & 0 & 0 & \\
\hline \multirow{3}{*}{ Placement of individual calf housing } & Outside & 10 & 11 & \\
\hline & Within a barn & 21 & 31 & 0.14 \\
\hline & Combination & 18 & 8 & 0.02 \\
\hline \multirow[t]{2}{*}{ Cleaning of individual calf housings } & Daily & 1 & 5 & \\
\hline & After calf left the housing & 49 & 45 & 0.20 \\
\hline Group housing of calves preweaning & Yes & 38 & 28 & 0.06 \\
\hline \multirow[t]{4}{*}{ Place of preweaning group housing ${ }^{4}$} & Outside & 4 & 1 & \\
\hline & Barn for young stock and calves & 15 & 10 & 0.44 \\
\hline & Within the cows barn & 18 & 16 & 0.78 \\
\hline & Combination & 1 & 1 & 0.94 \\
\hline \multirow[t]{2}{*}{ Group composition preweaning $^{4}$} & Calves of the same age group & 7 & 1 & \\
\hline & Calves of different ages & 31 & 27 & 0.13 \\
\hline \multirow[t]{2}{*}{ Group size preweaning (no. of calves) ${ }^{4}$} & $\operatorname{Median}^{2}$ & 6.0 & 5.5 & 0.22 \\
\hline & $\mathrm{IR}^{3}(25$ to $75 \%)$ & 4.0 to 9.5 & 4.0 to 8.3 & \\
\hline
\end{tabular}

${ }^{1}$ Case farms are farms with the presence of diarrhea; control farms are farms without calf diarrhea.

${ }^{2}$ Variable was not categorized; continuous variable.

${ }^{3} \mathrm{IR}=$ interquartile range.

${ }^{4}$ As the focus of the study was on preweaned calves, only data of farms with preweaning group housing $(\mathrm{n}=66)$ are shown.

BW, usually in 2 meals per day. Weaning on farm was mainly dependent on the animals' age. The median age at weaning on farms with diarrhea was $10.0 \mathrm{wk}$ (IR 8.0 to 12.0 ) and on farms without diarrhea was $9.0 \mathrm{wk}$ (IR 8.0 to 12.0). On none of the farms was the amount of solid feed eaten by the calf before weaning or BW examined and documented.

Hay was offered to the calves from the second week of life on 79 farms (41 case and 38 control farms). Silage was generally not fed to preweaned animals. On 68 farms, calves had free access to concentrates starting within the first 3 wk of life. On 25 farms, calves did not receive any concentrates before the third week of life; on 7 farms, only some calves received concentrates, depending on sex (when male calves were sold for veal production) and other factors. None of the variables concerning calf feeding differed between case and control farms.

\section{Hygiene Scores}

On 94 farms, calves were categorized as clean or mildly dirty. On 5 farms, calves were moderately dirty, and on only 1 farm were calves severely soiled. A similar distribution was found concerning calf housing. On 88 of the farms, calf housing areas were not soiled or were mildly soiled. Housing was categorized as moderately dirty on 10 farms and as severely soiled on 2 farms.

\section{Diseases}

Overall, 382 calves were examined on 100 farms, 205 of which were on case farms. Of these 205 calves, 79 animals $(39 \%)$ suffered from acute diarrhea the time of the farm visit. The average age of diarrheic calves was $16 \pm 11 \mathrm{~d}$. On 19 (10 case and 9 control) farms, umbilical infections (swelling, increased local temperature, and pain) were diagnosed. Acute respiratory tract disease was detected on 8 ( 7 case and 1 control) farms.

\section{Farm and Management Characteristics Associated with Diarrhea}

Sixteen variables with a $P$-value $\leq 0.2$ by univariable regression test were used in the multiple test. These variables were number of cows, presence of other farm 
Table 4. Data on standard calf feeding on the 100 visited farms

\begin{tabular}{|c|c|c|c|c|}
\hline Variable & Category & \multicolumn{2}{|c|}{ Number of farms ${ }^{1}$} & $P$-value \\
\hline \multirow[t]{2}{*}{ Milk feeding } & Whole milk & 44 & 40 & \\
\hline & Both & 5 & 5 & 0.20 \\
\hline \multirow[t]{2}{*}{ Feeding waste milk to calves } & No & 8 & 9 & \\
\hline & Only to male calves & 24 & 24 & 0.84 \\
\hline \multirow[t]{2}{*}{ Quantity of milk fed } & Ad libitum & 2 & 2 & \\
\hline & Restricted ( 10 to $12 \%$ of calf BW) & 48 & 48 & \\
\hline \multirow[t]{3}{*}{ Type of feeding } & Bucket with artificial teat & 49 & 46 & \\
\hline & Bucket without artificial teat & 0 & 2 & 0.54 \\
\hline & Automated milk feeder & 1 & 2 & 0.99 \\
\hline \multirow[t]{2}{*}{ Cleaning of bucket after each feeding } & No & 2 & 1 & \\
\hline & Yes & 48 & 49 & 0.62 \\
\hline Weaning age (wk) & $\mathrm{IR}^{3}(25$ to $75 \%)$ & 8.0 to 12.0 & 8.0 to 12.0 & \\
\hline \multirow[t]{3}{*}{ Access to hay from wk 2 of life } & No & 9 & 9 & \\
\hline & Yes & 41 & 38 & 0.75 \\
\hline & Variable & 0 & 3 & 0.69 \\
\hline \multirow[t]{3}{*}{ Access to concentrates from first 3 wk of life } & No & 12 & 13 & \\
\hline & Yes & 33 & 35 & 0.28 \\
\hline & Variable & 5 & 2 & 0.26 \\
\hline \multirow[t]{3}{*}{ Access to water preweaning } & No & 7 & 4 & \\
\hline & Free access & 19 & 22 & 0.42 \\
\hline & Restricted access & 24 & 24 & 0.73 \\
\hline
\end{tabular}

${ }^{1}$ Case farms are farms with the presence of diarrhea; control farms are farms without calf diarrhea.

${ }^{2}$ Variable was not categorized; continuous variable.

${ }^{3} \mathrm{IR}=$ interquartile range.

animals on farm (no/yes), animal caretaker [only family/employee(s)], presence of a calving pen (no/yes), usage of the calving pen for diseased animals (no/yes), cleaning of the calving pen after each use (no/yes), umbilical care postpartum (no/yes), cow-calf separation postpartum (immediately/within $24 \mathrm{~h}$ ), prepartum dam vaccination (no/yes), type of individual calf housing (synthetic igloo/wooden box/combination), placement of individual calf housing (outdoors/within barn/ combination), days of individual calf housing, cleaning of individual calf housing (dry/water), group housing of calves (same age group/different ages), group size, feeding of milk or milk replacer (milk/milk replacer), and respiratory tract disease (absent/present on farm). Type and placement of individual calf housing showed a high correlation (Spearman correlation $r=0.73$ ). Consequently, only the variable "placement of individual calf housing" was chosen for the model. After backward stepwise elimination of nonsignificant variables, a minimal model containing only significant variables was obtained. This minimal model consisted of 5 variables: herd size, presence of farm animals other than cattle on farm, cleaning of the calving pen, placement of in- dividual calf housing, and the presence of respiratory tract disease in calves on farm (Table 5). A greater herd size, expressed by the number of dairy cows, increased the odds of calf diarrhea on farm [odds ratio $(\mathbf{O R})$ 1.05, 95\% CI: 1.00 to $1.10 ; P=0.03$ ]. Furthermore, the presence of other farm animals was a risk factor (OR 26.89, 95\% CI: 2.64 to $273.5 ; P=0.01$ ). On farms where the calving area was cleaned after each calving, calves had decreased odds for calf diarrhea compared with farms where calves were born in calving areas only cleaned seldom or several times per year (OR 0.12, 95\% CI: 0.02 to $0.79 ; P=0.03)$. Placement of individual calf housing in a barn (either in a barn only for calves and young stock or in the cows' barn) versus outdoors decreased the risk of diarrhea (OR 0.02, 95\% CI: 0.00 to $0.47 ; P=0.01)$. Additionally, the presence of respiratory tract disease was associated with diarrhea on farm (OR 52.49, 95\% CI: 1.26 to $2,181.83 ; P=0.04$ ).

\section{DISCUSSION}

This study surveyed and described management practices in calf rearing on dairy farms in Austria to 
Table 5. Multiple analyses of risk factors for the appearance of calf diarrhea on the 100 visited dairy farms ${ }^{1}$

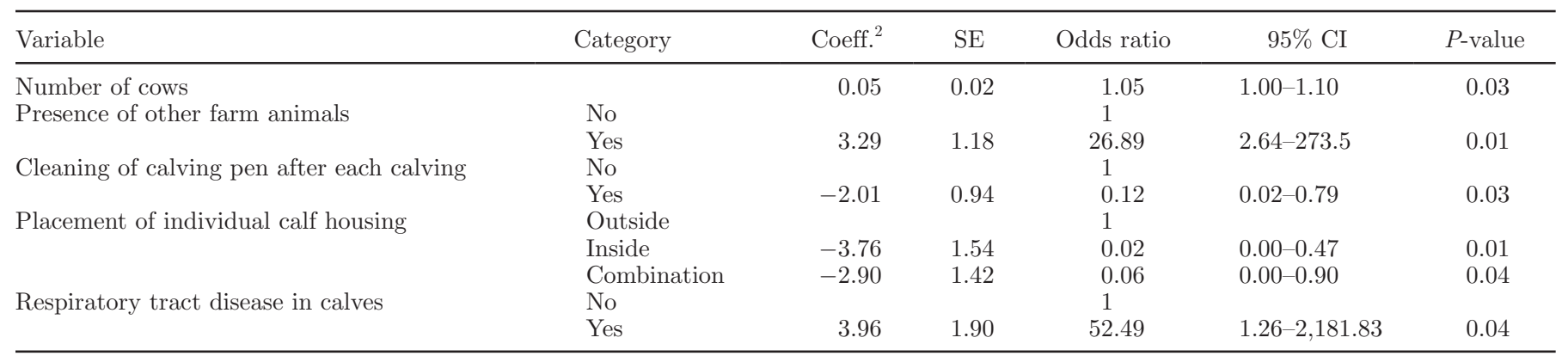

${ }^{1}$ Hosmer-Lemeshow: $P=0.98$.

${ }^{2}$ Coeff. $=$ regression coefficient.

identify risk factors for diarrhea on these farms. The sample size of 100 farms was within the range of similar studies (Healy et al., 2004; Dippel et al., 2009; SauterLouis et al., 2012). With this sample size, an OR of $\geq 3.5$ for a risk factor prevalent at $20 \%$ would be significant (statistical power of $80 \%$ ). A greater sample size might have increased the validity but sample size in this study was limited by time and funding resources.

\section{Farm Characteristics}

Regarding farm characteristics, the type of the cow facilities, breed, and caretaker were similar between farms. The average number of cows per farm (34 cows in our study) was larger than the overall average in the 2 visited regions, with 18 and 21 cows per farm, respectively, as reported by the Austrian Association of Cattle Breeders (ZAR, 2010). This might be influenced by selection of the farms being based exclusively on the presence of diarrhea. It is likely that very small farms might have been recognized as diarrhea problem farms less often because only a few calves were present during the selection period. This might have biased the outcome and has to be taken into account when interpreting the results. In this study, the presence of diarrhea was significantly associated with herd size. One possible explanation for the association between farm size and diarrhea could be that although farms in Austria have become larger in recent years, additional personnel were not employed on the surveyed farms. Even on farms with up to 115 cows, no employees were present, which could lead to a decrease in the time that the farmer can spend on calf care. Similar results concerning the association between the appearance of diarrhea and the herd size were obtained by Vaarst and Sørensen (2009) in Denmark. Furthermore, Frank and Kaneene (1993) identified an increased incidence of calf diarrhea for larger herds, explained by greater housing density that could lead to larger disease outbreaks. Kehoe et al. (2007) reported better colostrum management in smaller farms, which could also reduce the prevalence of disease in young calves.

Another variable significantly associated with diarrhea was the presence of farm animals other than cattle on farm. Other farm animals can host pathogens causing calf diarrhea (e.g., cryptosporidia; McGuirk, 2008) and therefore be a risk factor on farms.

\section{Management Around Calving and Care of the Newborn}

The literature concerning the importance and influence of the calving area on calf health is contradictory (Frank and Kaneene, 1993; Bendali et al., 1999; Pithua et al., 2009). A calving pen was present more often on case farms in the current study than on control farms $(P=0.02)$. Cleaning of such an area after each calving significantly reduced the odds of calf diarrhea on farm, as shown by the multiple analyses. A consequent cleaning was performed on only $19 \%$ of the farms with a calving area. The increased appearance of diarrhea on farms with a calving pen could therefore be explained by a lack of hygiene and the use of this area for diseased animals. This might lead to a high degree of contamination with pathogens and consequently to high infection pressure on the newborn calf. We can conclude that regular hygienic measures in the calving area should be implemented to reduce the risk of calf morbidity, as shown in other studies (Frank and Kaneene, 1993; Bendali et al., 1999).

Another factor that might influence the risk for diarrhea is the time the calf spends within the calving area with its mother, especially when hygiene is poor. This factor was not a risk factor on the visited farms.

The importance of an adequate colostrum supply, and therefore the passive transfer of immunoglobulins, for calf health is well known. Time of first colostrum feeding, as well as colostrum quantity and quality, plays an important role (Weaver et al., 2000; Barrington et al., 2002; Svensson and Liberg, 2006). According to the 
statements of the farmers on the visited farms, calves received colostrum within $6 \mathrm{~h}$ after birth (as required by legislation; European Community, 2008) on 99\% of the farms. On 7 of these farms, calves were allowed to suckle their dam, representing a risk factor associated with failure of passive transfer (Trotz-Williams et al., 2008). None of the factors associated with colostrum supply had a significant effect on the appearance of diarrhea in our study. This is in accordance with other studies (Bendali et al., 1999; Gulliksen et al., 2009) and can be explained by the high similarity between farms and by the fact that the time of feeding first colostrum is regulated by law. Another interesting finding in this context was that colostrum quality was not controlled on any of the farms except for one.

Another factor examined was the use of a prepartum dam vaccination against rotavirus and coronavirus as well as against different $E$. coli, which was performed on only 17 farms. This prophylactic measure was performed on farms with and without diarrhea and had no influence on the presence of diarrhea on the surveyed farms. Possible reasons could be that not all cows and heifers on the farm have been vaccinated and the presence of other pathogens such as cryptosporidia.

\section{Calf Housing}

On almost all of the visited farms, calves were housed individually within the first weeks of life, as described by Marcé et al. (2010). Individual calf housing is commonly advised because it may lead to a decreased pathogen load (Barrington et al., 2002); in epidemiologic studies, group size rather than grouping itself was associated with an increased risk for morbidity and mortality (Svensson et al., 2003; Maunsell and Donovan, 2008). Nevertheless, in individual calf housing, it is possible to feed calves individually according to their special needs and it is easier to control animals and recognize certain abnormalities. Housing of calves outside the barn is thought to reduce the risk of disease (Marcé et al., 2010), as indoor housing has disadvantages such as an increased pathogen load and risk for disease transmission. This, however, was not the case on farms in the present study, in which greater odds for diarrhea were found for calves housed in igloos outside the barn compared with individual housing in a barn. This is in accordance with a study performed in the United Kingdom by Johnson et al. (2013). Possible explanations could be the cold environment and exposure of the calves to considerably greater climate changes (Vasseur et al., 2010). This could be true for the 2 areas of Austria visited in the current study because minimum temperatures were -14 to $-19^{\circ} \mathrm{C}$ during December and January 2009 and 2010. Maxi- mum temperature differences were registered during April with a difference in mean daily temperatures up to $19^{\circ} \mathrm{C}$ (ZAMG, 2009-2010). An advantage of indoor housing mentioned often by farmers is easier and better monitoring of the calves.

In the present study, none of the variables concerning grouping (i.e., age at grouping, number of animals per group, and grouping of animals of the same age or not) was significantly associated with the appearance of diarrhea on farm. This might be because of the relatively small group size, with a median of 6 animals (interquartile range 4 to 8 ) on the visited farms. Furthermore, grouping relatively late in the calves' life (median 6 wk, interquartile range 4 to $8 \mathrm{wk}$ ) could have positively influenced morbidity, because the risk for diarrhea is highest in the first $3 \mathrm{wk}$ of life (Bendali et al., 1999; Svensson and Liberg, 2006).

Although the importance of hygienic measures in association with calf diarrhea is well known (Barrington et al., 2002; Maunsell and Donovan, 2008), hygiene is an often neglected measure, as could be seen in our results. Standard operating procedures for cleaning and disinfection of calf housing were not present on any of the visited farms.

\section{Calf Feeding}

As nutrition in calves affects calf immunity, and therefore morbidity and mortality (Nonnecke et al., 2003), data concerning this management area were evaluated.

On almost all farms (96\%), calves were fed restricted amounts of milk. The reason for a restricted milk feeding program is that calves are forced to ingest concentrates earlier and at greater amounts, stimulating rumen development (Drackley, 2008). This procedure, however, does not take into account that these effects are of minor importance within the first $3 \mathrm{wk}$ of life and that calves cannot meet their energy requirements by an additional intake of concentrates during this time of life (Jasper and Weary, 2002; Sweeney et al., 2010). In contrast, several studies (reviewed by Khan et al., 2011; Silper et al., 2014) showed that milk fed at amounts greater than 10 to $12 \%$ of calf BW had a positive influence on the calf performance, whereas deficiencies in nutrition may lead to depressed immunity in calves and increase morbidity (Nonnecke et al., 2003).

On most of the visited farms (84\%), whole milk was fed. Waste milk was offered to the calves on $82 \%$ of the farms. Whole milk may have advantages over milk replacer in terms of greater energy content and a better balance of nutrients (Davis and Drackley, 1998; Godden et al., 2005). This might therefore improve calf immunity and lead to a decreased disease rate (Godden 
et al., 2005). Additional advantages of feeding whole milk are that it is easier and less error-prone than feeding milk replacer (e.g., errors related to products with inadequate protein or incorrect mixing ratios) and that both milk produced over the available quota and waste milk can be used (Vasseur et al., 2010). Nevertheless, using whole milk and especially waste milk poses some risks, such as the transmission of pathogens and the transfer of drug residues to calves (Selim and Cullor, 1997). In the present study, no effect of milk feeding management on the appearance of diarrhea was found. This might be due to the high similarity in feeding management between farms.

\section{Hygiene Score}

In the present study, no association was observed between calf or calf housing hygiene scores and the presence of diarrhea, in accordance with the findings of Lundborg et al. (2005). One possible explanation is that the scores were similar on most of the farms. This in turn could be explained by the fact that fresh straw was added frequently, even when calf housing was not cleaned regularly.

\section{Diseases}

In the present study, the presence of respiratory tract disease was significantly associated with diarrhea. These results have to be interpreted with care as farms were visited only once and, therefore, results represent a snapshot. Furthermore, the number of farms with calves suffering from respiratory tract disease was low. Consequently, the confidence for this variable was low. Nevertheless, associations between respiratory tract disease and diarrhea in calves have been observed by other authors (Johnson et al., 2013; Woolums et al., 2013). The association can be explained by a lack of hygiene and impairment of the calf immunity, which predisposes calves to different multifactorial diseases. Furthermore, one disease may negatively affect calf performance and consequently predispose to other diseases. Pathogens such as coronaviruses often present on farms and have a predilection for the intestinal and respiratory tract (Boileau and Kapil, 2010).

When interpreting factors that are significantly associated with the outcome variable in a statistical model, it has to be considered that associations may not necessarily reflect actual causal or protective relationships. Furthermore, factors not analyzed in this study could have influenced the incidence of diarrhea.

\section{CONCLUSIONS}

Many calf rearing management factors were similar between the visited farms, especially in areas regulated by law. These factors include colostrum management, housing, and feeding procedures. Consequently, no significant influences of these factors on the appearance of calf diarrhea were detected in this study. In contrast, other areas, such as hygiene measures, differed between farms and showed, in part, a significant association with the presence of calf diarrhea on the farm. Variables significantly related to diarrhea on farm were farm size, presence of other farm animals on the farm, cleaning of the calving area after each calving, placement of individual calf housing, and the presence of respiratory tract disease. Consequently, the possible influence of these factors on the appearance of calf diarrhea should be taken into account. Improving these areas may lead to a decrease in diarrhea and might consequently reduce calf morbidity and mortality and be of economic importance.

\section{ACKNOWLEDGMENTS}

This study was financed by the University of Veterinary Medicine (Vienna, Austria) by a start-up project (Profillinie 2).

\section{REFERENCES}

Barrington, G. M., J. M. Gay, and J. F. Evermann. 2002. Biosecurity for neonatal gastrointestinal diseases. Vet. Clin. North Am. Food Anim. Pract. 18:7-34.

Bendali, F., M. Sanaa, H. Bichet, and F. Schelcher. 1999. Risk factors associated with diarrhoea in newborn calves. Vet. Res. 30:509522 .

Berge, A. C., D. A. Moore, T. E. Besser, and W. M. Sischo. 2009. Targeting therapy to minimize antimicrobial use in preweaned calves: Effects on health, growth, and treatment costs. J. Dairy Sci. 92:4707-4714.

Boileau, M. J., and S. Kapil. 2010. Bovine coronavirus associated syndromes. Vet. Clin. North Am. Food Anim. Pract. 26:123-146.

Davis, C. L., and J. K. Drackley. 1998. The Development, Nutrition, and Management of the Young Calf. Iowa State University Press, Ames.

Dippel, S., M. Dolezal, C. Brenninkmeyer, J. Brinkmann, S. March, U. Knierim, and C. Winckler. 2009. Risk factors for lameness in freestall-housed dairy cows across two breeds, farming systems, and countries. J. Dairy Sci. 92:5476-5486.

Drackley, J. K. 2008. Calf nutrition from birth to breeding. Vet. Clin. North Am. Food Anim. Pract. 24:55-86.

European Community. 2008. Council Directive 2008/119/EC: Laying down minimum standards for the protection of calves. Accessed Nov. 4, 2013. http://eur-lex.europa.eu/LexUriServ/LexUriServ.do? uri=CELEX:32008L0119:en:NOT.

Frank, N. A., and J. B. Kaneene. 1993. Management risk factors associated with calf diarrhea in Michigan dairy herds. J. Dairy Sci. 76:1313-1323.

Godden, S. M., J. P. Fetrow, J. M. Feirtag, L. R. Green, and S. J. Wells. 2005. Economic analysis of feeding pasteurized nonsaleable milk versus conventional milk replacer to dairy calves. J. Am. Vet. Med. Assoc. 226:1547-1554.

Gulliksen, S. M., E. Jor, K. I. Lie, I. S. Hamnes, T. Loken, J. Akerstedt, and O. Østerås. 2009. Enteropathogens and risk factors for diarrhea in Norwegian dairy calves. J. Dairy Sci. 92:5057-5066.

Healy, A. M., D. Hannon, K. L. Morgan, E. Weavers, J. D. Collins, and M. L. Doherty. 2004. A paired case-control study of risk factors for scrapie in Irish sheep flocks. Prev. Vet. Med. 64:73-83. 
Jasper, J., and D. M. Weary. 2002. Effects of ad libitum milk intake on dairy calves. J. Dairy Sci. 85:3054-3058.

Johnson, K. F., C. C. Burns, C. M. Wathes, and D. C. Wathes. 2013. Determining risk factors for poor growth, contagious disease and mortality in a cohort of UK dairy heifer calves. Page 73 in Proc. 15th Int. Conf. Product. Dis. Farm Anim. (ICPD), Uppsala, Sweden. Swedish University of Agricultural Sciences (SLU), Uppsala, Sweden.

Kehoe, S. I., B. M. Jayarao, and A. J. Heinrichs. 2007. A survey of bovine colostrum composition and colostrum management practices on Pennsylvania dairy farms. J. Dairy Sci. 90:4108-4116.

Khan, M. A., D. M. Weary, and M. A. von Keyserlingk. 2011. Invited review: Effects of milk ration on solid feed intake, weaning, and performance in dairy heifers. J. Dairy Sci. 94:1071-1081.

Larson, L. L., F. G. Owen, R. D. Albright, R. D. Appleman, R. C. Lamb, and L. D. Miller. 1977. Guidelines toward more uniformity in measuring and reporting calf experimental data. J. Dairy Sci. 60:989-991.

Lundborg, G. K., E. C. Svensson, and P. A. Oltenacu. 2005. Herd-level risk factors for infectious diseases in Swedish dairy calves aged 0-90 days. Prev. Vet. Med. 68:123-143.

Marcé, C., R. Guatteo, N. Bareille, and C. Fourichon. 2010. Dairy calf housing systems across Europe and risk for calf infectious diseases. Animal 4:1588-1596.

Maunsell, F., and G. A. Donovan. 2008. Biosecurity and risk management for dairy replacements. Vet. Clin. North Am. Food Anim. Pract. 24:155-190.

McGuirk, S. M. 2008. Disease management of dairy calves and heifers. Vet. Clin. North Am. Food Anim. Pract. 24:139-153.

Nonnecke, B. J., M. R. Foote, J. M. Smith, B. A. Pesch, and M. E. Van Amburgh. 2003. Composition and functional capacity of blood mononuclear leukocyte populations from neonatal calves on standard and intensified milk replacer diets. J. Dairy Sci. 86:3592-3604.

Pithua, P., S. J. Wells, S. M. Godden, and E. A. Raizman. 2009. Clinical trial on type of calving pen and the risk of disease in Holstein calves during the first $90 \mathrm{~d}$ of life. Prev. Vet. Med. 89:8-15.

Radostits, O. M., C. C. Gay, K. W. Hinchcliff, and P. D. Constable. 2007. Examination of the patient. Pages 8-21 in Veterinary Medicine: A Textbook of the Diseases of Cattle, Horses, Sheep, Pigs, and Goats. 10th ed. Saunders/Elsevier Limited, Philadelphia, PA.

Sauter-Louis, C., A. Carlin, A. Friedrich, A. Assad, F. Reichmann, G. Rademacher, C. Heuer, and W. Klee. 2012. Case control study to investigate risk factors for bovine neonatal pancytopenia (BNP) in young calves in southern Germany. Prev. Vet. Med. 105:49-58.

Selim, S. A., and J. S. Cullor. 1997. Number of viable bacteria and presumptive antibiotic residues in milk fed to calves on commercial dairies. J. Am. Vet. Med. Assoc. 211:1029-1035.

Silper, B. F., A. M. Lana, A. U. Carvalho, C. S. Ferreira, A. P. Franzoni, J. A. Lima, H. M. Saturnino, R. B. Reis, and S. G. Coelho. 2014. Effects of milk replacer feeding strategies on performance, ruminal development, and metabolism of dairy calves. J. Dairy Sci. 97:1016-1025.
Svensson, C., and P. Liberg. 2006. The effect of group size on health and growth rate of Swedish dairy calves housed in pens with automatic milk-feeders. Prev. Vet. Med. 73:43-53.

Svensson, C., A. Linder, and S. O. Olsson. 2006. Mortality in Swedish dairy calves and replacement heifers. J. Dairy Sci. 89:4769-4777.

Svensson, C., K. Lundborg, U. Emanuelson, and S. O. Olsson. 2003. Morbidity in Swedish dairy calves from birth to 90 days of age and individual calf-level risk factors for infectious diseases. Prev. Vet. Med. 58:179-197.

Sweeney, B. C., J. Rushen, D. M. Weary, and A. M. de Passille. 2010 Duration of weaning, starter intake, and weight gain of dairy calves fed large amounts of milk. J. Dairy Sci. 93:148-152.

Thrusfield, M., C. Ortega, I. de Blas, J. P. Noordhuizen, and K. Frankena. 2001. WIN EPISCOPE 2.0: Improved epidemiological software for veterinary medicine. Vet. Rec. 148:567-572.

Tierhaltungsverordnung. 2004. Verordnung der Bundesministerin für Gesundheit und Frauen über die Mindestanforderungen für die Haltung von Pferden und Pferdeartigen, Schweinen, Rindern, Schafen, Ziegen, Schalenwild, Lamas, Kaninchen, Hausgeflügel, Straußen und Nutzfischen. Accessed Nov. 4, 2013. http://www.ris. bka.gv.at/Dokument.wxe?Abfrage $=$ BgblAuth\&Dokumentnummer =BGBLA_2004_II_485.

Torsein, M., A. Lindberg, C. H. Sandgren, K. P. Waller, M. Tornquist, and C. Svensson. 2011. Risk factors for calf mortality in large Swedish dairy herds. Prev. Vet. Med. 99:136-147.

Trotz-Williams, L. A., K. E. Leslie, and A. S. Peregrine. 2008. Passive immunity in Ontario dairy calves and investigation of its association with calf management practices. J. Dairy Sci. 91:3840-3849.

Vaarst, M., and J. T. Sørensen. 2009. Danish dairy farmers' perceptions and attitudes related to calf-management in situations of high versus no calf mortality. Prev. Vet. Med. 89:128-133.

Vasseur, E., F. Borderas, R. I. Cue, D. Lefebvre, D. Pellerin, J. Rushen, K. M. Wade, and A. M. de Passillé. 2010. A survey of dairy calf management practices in Canada that affect animal welfare. J. Dairy Sci. 93:1307-1315.

Weaver, D. M., J. W. Tyler, D. C. VanMetre, D. E. Hostetler, and G. M. Barrington. 2000. Passive transfer of colostral immunoglobulins in calves. J. Vet. Intern. Med. 14:569-577.

Woolums, A. R., R. D. Berghaus, D. R. Smith, B. J. White, T. J. Engelken, M. B. Irsik, D. K. Matlick, A. L. Jones, R. W. Ellis, I. J. Smith, G. L. Mason, and E. R. Waggoner. 2013. Producer survey of herd-level risk factors for nursing beef calf respiratory disease. J. Am. Vet. Med. Assoc. 243:538-547.

ZAMG (Central Institute for Meteorology and Geodynamics). 20092010. Monthly/annual review of meteorological stations in Austria. 2009 and 2010. Accessed Feb. 7, 2014. http://www.zamg. ac.at/fix/klima/jb2009/index_e.html.

ZAR (Association of Austrian Cattle Breeders). 2010. Annual report of the Association of Austrian Cattle Breeders, 2010 ed. Accessed Nov. 4, 2013. http://www.zar.at/article/archive/18980. 